\title{
Significance of Clinical Treatments on Peripheral Nerve and its Effect on Nerve Regeneration
}

\section{Michael Hsu*}

Myoscience, Inc., Redwood City, USA

*Corresponding author: Michael Hsu, Myoscience Inc., 1600 Seaport Blvd., Suite 450, Redwood City, CA 94063, USA, Tel: 1-415-754-8007; Email: mhsu@myoscience.com

Rec date: May 9, 2014, Acc date: Jun 21, 2014, Pub date: Jun 24, 2014

Copyright: (c) 2014 Hsu M. This is an open-access article distributed under the terms of the Creative Commons Attribution License, which permits unrestricted use, distribution, and reproduction in any medium, provided the original author and source are credited

\begin{abstract}
Some neurological disorders that cannot be managed with medication can alternatively be directly treated either at the sensory and/or motor nerve(s). In particular, chronic pain and/or muscle spasticity are a couple types of symptoms that can potentially be treated at the associated nerve. Various chemicals and medical devices are currently being employed in the clinic to treat peripheral nerves. Treatment of sensory nerves is typically used to attenuate chronic pain symptoms, while motor nerves are targeted for spasticity symptoms. A majority of treatment methods currently used in the field involve nerve injury and denervation of the target tissue through different mechanisms of action. Depending on the type and severity of the treatment, the nerve may or may not fully regenerate to a normal state. This article will review the various types of clinical methods used to treat neurological disorders and discuss the possible outcomes of nerve regeneration.
\end{abstract}

Keywords: Wallerian degeneration; Peripheral nervous system; Focused cold therapy; Movement disorder; Spasm; Pain; Nerve regeneration

\section{Summary}

Neurological disorders that cannot be managed with medication can alternatively be treated directly at either the sensory and/or motor nerve(s). In particular, chronic pain and/or muscle spasticity are some conditions that can be treated at the associated nerve. Various chemicals and medical devices are currently employed in the clinic to treat peripheral nerves. Treatment of sensory nerves is typically used to attenuate chronic pain symptoms, while motor nerves are targeted for spasticity symptoms. A majority of treatment methods currently used in the field involve nerve injury and denervation of the target tissue through different mechanisms of action. Depending on the type and severity of the treatment, the nerve may or may not fully regenerate to a normal state. This article will review the various types of clinical methods used to treat neurological disorders and discuss the possible outcomes of nerve regeneration.

\section{Introduction}

Millions of people worldwide suffer from neurological diseases relating to chronic pain and/or spasticity [1-3]. Medication may not be a suitable option for some patients due to unacceptable systemic side effects and/or ineffectiveness in reducing the symptom(s). Some of the side effects of using pain medications include nausea, addiction, drowsiness, depression, and decreased effectiveness over time. While side effects of anti-spasticity drugs include muscle weakness, drowsiness, nausea, and psychological effects. Alternative methods may be employed in the direct treatment of the peripheral motor or sensory nerve implicated in the disease. The main objective of treating the peripheral nerves is to disrupt either the pain signaling of the sensory nerve or the involuntary signaling of muscle contraction by the motor nerves. Treatments directly targeting the nerve helps reduce the possibility of systemic side effects associated with either pain or anti-spasticity medications.

While the neurons in the central nervous system (CNS) are unable to regenerate after injury, axonal regeneration in peripheral nerves can be robust [4]. In the CNS, various inhibitory factors (ie Nogo, MAG, OMgp, etc) expressed by the surrounding cells (ie myelin) and present in the extracellular space, prevent nerve regeneration from occurring [4]. In contrast, the peripheral nerve system (PNS) responds to injury by upregulating various neurotrophic and axon guidance signaling factors to promote regeneration [5]. An injured nerve axon undergoes a complex process to restore normal function of conducting signal to/ from its target tissue. Upon injury, the axon begins a degeneration process at the injury site and progresses distally. A small distance of retrograde degeneration occurs, but the proximal portion of the nerve body and axon largely remains intact [6]. Concurrently, the myelin sheath also undergoes a degeneration phase. Macrophages and Schwann cells function to clear the cellular debris. Regeneration of the axon immediately follows with the Schwann cells undergoing a proliferation and differentiation phase to form the scaffolding for the axon. Various cell signaling factors occur between the neuron, Schwann cells, and the surrounding environment promotes the elongation and guidance of the regenerating axon. Greater detail of the molecular and cellular mechanisms of peripheral nerve regeneration can be found in literature [7-9]. Depending on the nature of the damage, the peripheral nerve may or may not be able to fully regenerate to a normal morphological and/or functional state [10]. The ability of the nerve to regenerate predominantly relies on how well the surrounding nerve structure (endo-, peri-, and epi-neurium) remains intact. This article will compare some common treatment methods employed in the clinic and its effect on the peripheral nerve's regenerative outcome. 


\section{Nerve Injury Classification and Expected Recovery}

Characterization and classification of nerve injuries have been well established for many decades. Several research and review articles examine the molecular, pathological, and clinical characteristics of nerve injury in great detail and two commonly known nerve injury severity scales have been published. Sir Herbert Seddon first published a 3-point nerve injury scale in 1943 [11]. Later, in 1951 Sir Sydney Sunderland published a 5-point scale which gave more resolution to Seddon's scale [12] (Table 1).

\begin{tabular}{|l|l|l|}
\hline Description & $\begin{array}{l}\text { Seddon } \\
\text { Scale }\end{array}$ & $\begin{array}{l}\text { Sunderland } \\
\text { Scale }\end{array}$ \\
\hline Neuropraxia - Disruption of nerve conduction, but nerve structure and axon remain intact. & I & I \\
\hline $\begin{array}{l}\text { Axonotmesis - Disruption of nerve conduction and axon degeneration, but remaining nerve structure (endoneurium, perineurium, } \\
\text { and epineurium) remains intact. }\end{array}$ & II & II \\
\hline Axonotmesis with disruption of the endoneurium, but the perineurium and epineurium remains intact. & II & III \\
\hline Axonotmesis with disruption of the endoneurium and perineurium, but epineurium remains intact. & III & IV \\
\hline Neurotmesis - Total transection of the nerve fiber. & V \\
\hline
\end{tabular}

Table 1: Nerve injury characteristic and comparison of the Seddon and Sunderland scales

First degree (neuropraxia) is the mildest form of nerve injury and is characterized by a disruption of the nerve's ability to transmit an action potential along the axon. Damaged myelin sheath localized at the injury site may occur, but the entirety of the nerve structure and the axon largely remains intact and unchanged. Full functional recovery from neuropraxia can range from minutes to a few weeks. Although this form nerve injury is not as widely studied as the more severe injuries, but pressure block and non-freezing low temperatures are typical methods used in basic research to study temporary nerve conduction blocks [12].

Second degree nerve injury is characterized by a degeneration process of the axon, also known as Wallerian degeneration. Nerve crush injury is typically the cause of Wallerian degeneration and is used as a model in basic research. Degeneration of the axon and myelin sheath occurs initially at the injury site, shortly followed by degeneration of the remaining distal portions of the axon and associated myelin sheath. The retrograde degeneration of the axon is limited to injury site while the nerve body remains unchanged. Wallerian degeneration results in a longer duration of functional loss as compared to neuropraxia. Functional recovery relies on the time it takes for the axon to regenerate and re-innervate the target organ. Depending on the distance of the axon injury site to the target site, the disruption of signaling can last from weeks to months. Numerous factors can affect the rate of axon regeneration which can range from 1 to $5 \mathrm{~mm}$ per day [13-15]. Reliability of axon regeneration also relies on the integrity of the surrounding endoneurial, perineurial, and epineurial structure. These structures acts as a scaffold to guide the regenerating axon for optimal recovery, while signaling factors promote axon regeneration. Depending on the extent of damage to these surrounding structures, the degree of nerve injury would be higher (see below). Furthermore, axonal regeneration relies on a complex interaction between the Schwann cells, macrophages, and the axon aid in regeneration and re-myelination of the nerve [16]. Some of the interactions among these cell types involve various signaling pathways, including Toll-like receptor activation, NF- $\kappa \mathrm{B}$ activation, and up-regulation of various interleukin cytokines [17]. The proper regulation of the various signaling factors helps coordinate the clearance of the cellular debris and direct the axon to its target site. Through this complex molecular and cellular interaction, the nerve is able to reliably regenerate and re-innervate its target organ for normal function.

Third degree injury involves Wallerian degeneration of the axon but also includes damage to the endoneurium. This type of injury is common with nerve stretch injuries. The endoneurium primarily consist of various collagen types, reticular fibers, and an extracellular matrix (ECM). The primary role of the endoneurium is to provide a scaffold for the Schwann cells and axon. Injury to the endoneurium can induce fibrosis and scarring within the endoneurial tube [18]. Due to the disruption of this path, axonal regeneration rate is diminished. Additionally, studies have shown axon regeneration to deviate from the disrupted endoneurial tube and into the intrafasicular structure; which, could lead to a potential neuroma formation [18]. Functional, but not complete, innervation of the target site can occur over a period of months to year(s) $[12,18,19]$.

Fourth degree injury involves Wallerian degeneration but also includes damage to the endoneurium, perineurium, and epineurium. This type of injury can be found in laceration or severe stretch injuries. The severity of this injury allows for the regenerating axon to grow into the extrafasicular structure, resulting in growth termination [20]. Increased scarring and fibrosis is more prevalent; therefore, promoting neuroma formation [12]. Without surgical intervention functional recovery is minimal, while surgical repair will allow for improved chances of useful functional recovery, but with incomplete reinnervation of the target tissue [21].

Fifth degree injury is the total transection of the nerve. This type of injury is commonly found in lacerations or amputations. Without surgical repair, total lack of functional recovery with scar and neuroma formation occurs. Due to the lack of the nerve scaffolding, axons will regenerate aberrantly at the injury site and will not be able to continue to the distal nerve stump [22]. Additionally, spontaneous and aberrant signaling from the injured sensory nerve result in neuropathic pain symptoms, commonly observed in amputation stump pain $[23,24]$. Some surgical methods used to repair nerve transection include suturing to join the proximal and distal stump, auto- or allo-grafting of nerve gaps, or use of biological or biosynthetic conduits [25]. These various methods allows for some percentage of the axons to regenerate along a scaffold and be able to reach the target organ. These methods 
allow for very limited success in functional and useful recovery in sensory and/or motor function. Continued research and development in the field is being carried out to determine the best materials and methods to promote a robust neuroregenerative response [26,27].

In general, the degree of nerve injury determines the ability for the nerve to regenerate over time. The milder forms of nerve injury (i.e. neuropraxia and axonotmesis) allow for normal nerve regeneration as the ability to minimize any structural changes to the scaffolding of the nerve allows for more complete regeneration of the axon. More severe injuries (i.e. axonotmesis with structural damage or neurotmesis) result in disruption of the nerve path which makes it more difficult or impossible for functional regeneration of the nerve.

\section{Treatments Utilized in the Clinic}

In cases where symptoms of a neurological disorder cannot be treated with medication, or an alternative treatment method is desired, a physician may consider directly treating the nerve. For example, chronic pain patients can be treated by disruption of the sensory nerve eliciting the pain. Similar methods can be used to treat the motor nerve for spasticity patients. Various methods are currently being employed to treat disorders related to the sensory and/or motor nerves. Typically the methods are used to disrupt signaling of these peripheral nerves to attenuate symptoms of the disorder. Each method produces vastly different mechanisms of action for disruption of nerve signaling, typically through some form of nerve injury. Below we will discuss the methods employed in the clinic and describe the mechanism involved and implications for the ability for nerve regeneration.

\section{Phenol and Alcohol Nerve Blocks}

Injection of either phenol or alcohol to the nerve has been used to treat pain and/or spasticity symptoms. The use of these neurolytic agents have been report since at least the early 1900's [28]. Examples of their use include, but are not limited to, the application for post-stroke related spasticity [29], neuromas [30], and pain [31]. These methods have demonstrated a loss of, or reduction in, nerve function which can last from 2 months to 3 years [32]. Both chemicals have different methods of action, but with similar clinical results.

At low concentrations $(<2 \%)$ phenol can be used as a short term anesthetic with minimal nerve injury [29]. The primary mechanism of action at lower concentrations of phenol is believed to be an disruption of ability for the nerve to produce an action potential across the axon membrane [33]. Phenol at the higher concentrations is generally known to cause non-selective destruction to tissue. Depending on the concentration used, phenol can induce axonal degeneration with some damage to the acellular nerve structure. It is not fully understood as to whether the mechanism of action is due to the denaturation of proteins in the nerve or by an ischemic injury to the neurovasculature [34]. Morphological analysis of nerves treated with phenol has found Wallerian degeneration does occur, while the epineurium remains intact. However, loss of cellular fatty elements, separation of myelin sheath, and axonal edema also occurs [35]. Based on these histological findings, the data indicate a minimum of second degree nerve injury with minimal to no loss of the endoneurial nerve structure at concentrations of $\sim 5-7 \%$. Further examination demonstrated that even though function recovery appears normal, force measurements showed a long term decrease in maximum tension as compared to both untreated control and the crush injury model [34]. In particular, higher concentrations $7.5-10 \%$ has been found to produce permanent anaesthesia and/or muscle weakness, thus indicating a disruption of the nerve scaffold structure [36]. This data indicates that, depending on concentration used, phenol can produce a second and/or third degree injury, where there may be a mild deficit in nerve regeneration.

Similar to phenol, use of different concentrations of alcohol will also give differing results. Low concentrations (4\% to $29 \%$ ) of alcohol are able to temporarily interrupt nerve conduction with minimal damage to the nerve. Higher concentrations of alcohol (30\% to 100\%) inhibit signaling and degenerates the nerve. At particularly high percentages (90\% to $100 \%$ ), histological examination indicates fibrosis surrounding the treatment site with a slower regeneration rate [28]. Similarly to phenol, alcohol is generally known to cause non-selective destruction of proteins in tissue types [29]. Additional reports indicate that the function of the treated nerves will have normal functional return over time [37]. Similarly to phenol, clinical duration of effect has been reported to last from a few months to years. This variable range of duration is likely to be due to numerous factors ranging from targeting of the nerve, type of nerve, and concentration used. Furthermore, both phenol and alcohol have been known to cause vascular injury; thus, playing a possible role in nerve degeneration and/or regeneration process [32]. Alcohol produces a second to third degree nerve injury. While concentrations closer to $30 \%$ are likely to produce a second degree injury, there is increasing likelihood of third degree injury at concentrations near $100 \%$.

The known evidence demonstrates that phenol and alcohol can create a temporary degeneration followed with normal regeneration both histologically and functionally. Higher concentrations may allow for a more effective treatment, but with increasing chance of third degree nerve injury and collateral damage to surrounding tissue structures.

\section{Cryoneuromodulation}

The use of freezing temperatures to treat chronic pain, also known as cryotherapy or cryoanalgesia, has been in use for many decades. Numerous reports have demonstrated the efficacy of freezing temperatures in attenuating various chronic pain symptoms ranging from trigeminal neuralgia to neuroma, and post-thoracotomy pain [38-43]. These reports have demonstrated pain relief ranging from a couple of months to a few years $[40,43]$.

Though the concept of using cold to treat sensory nerves has been in use since the mid-1800's [44], application to motor nerves had not been employed until recently. Cryoneuromodulation, a term which encompasses treatment of either sensory of motor nerves, occurs over a wide range of temperatures with treatment often occurring at temperatures as cold as $-196^{\circ} \mathrm{C}$ (liquid nitrogen coolant) or $-88^{\circ} \mathrm{C}$ (nitrous oxide coolant). While clinical case reports have demonstrated the use of non-freezing low temperatures to demonstrate transient attenuation of muscle spasticity or pain associated with sports-related injuries [45-47]. A recent preclinical report described the feasibility of using freezing temperatures to treat motor nerves for potentially treating movement disorders [48]. These results could be expected given that the mechanism of denervation and regeneration is similar for sensory and motor nerves [49]. Clinical trials are currently underway to determine the potential use of freezing temperatures as a viable option for treatment of upper limb spasticity (http:// www.clinicaltrials.gov; NCT01863901). Due to the short duration of 
non-freezing temperature cryotherapy, we will focus on freezing temperature cryoneuromodulation as this is a more common method for treating chronic neurological disorders.

The mechanism of action for tissues treated with temperatures as cold as $-196^{\circ} \mathrm{C}$ is based on both the final freezing temperature as well as the rate of cooling [50]. For this reason, there are multiple proposed modalities of injury including physical cell damage by intracellular ice formation, which occurs during cooling at a high rate. If the cooling occurs at a slow rate then an increase in extracellular solute concentration during the freezing process can cause the cells in the tissues to dehydrate thereby damaging cytoplasmic proteins [51]. In addition to either of the described mechanisms of action there may also be ischemic injury due to vascular damage $[51,52]$.

Histological studies have shown that for treatment of nerves with temperatures from $-20^{\circ}$ to $-60^{\circ} \mathrm{C}$ Wallerian degeneration occurs while leaving the endoneurium intact [53]. Additionally, a comparative study between crush lesion (a common model of Wallerian degeneration) and cryoneuromodulation treatment on a rat sciatic nerve showed comparable histological results of second degree injury [54]. Examination of tissue exposed to freezing temperature has found that cells are injured, but the surrounding acellular structures remain intact [55]. This feature aids in the preservation of the acellular structures of the endo-, peri-, and epi-neurium; allowing for normal axonal regeneration and return of function. Based on the morphological findings and reported normal return of function supports second degree degeneration at temperatures as low as $-60^{\circ} \mathrm{C}$.

At temperatures at $-100^{\circ} \mathrm{C}$ to $-180^{\circ} \mathrm{C}$, histological analysis show extended damage to the basal membrane and collagen proliferations. These markers indicated endoneurial and perineurial damage, but the epineurium appeared to remain intact [53]. The lower temperatures have also demonstrated a longer duration of electrophysiological and functional disruption when compared to temperatures warmer than $-60^{\circ} \mathrm{C}[53,55]$. These findings demonstrate that lower temperatures $\left(<-100^{\circ} \mathrm{C}\right)$ creates a third degree nerve injury. These colder temperatures can create a longer term efficacy of reduced muscle spasticity or pain attenuation as compared to the milder freezing temperatures. Due to the acellular structure damage of the endoneurium and perineurium, there is a risk of neuroma formation and reduced motor or sensory function of the target tissue.

\section{Radiofrequency}

Radiofrequency is commonly used to treat pain chronic pain syndromes with some use for motor nerves. Conventional (CRF) and pulsed (PRF) radiofrequency are 2 forms of RF technologies currently employed in the clinic. CRF is continuously applies radiofrequency in a continuous fashion and heats the tissue to approximately $60-80^{\circ} \mathrm{C}$. $\mathrm{PRF}$ applies the radiofrequency at a higher voltage in a pulsed fashion and heats the tissue to approximately $40-42^{\circ} \mathrm{C}$. In between bursts of current, the inactive phase allows the heat to dissipate. Ongoing research has shown that these two different methods of energy application have a different mechanism of action [56,57].

The high temperatures employed by CRF are the primary cause of tissue injury. The exposure temperatures are known to cause a coagulative necrosis to both cellular and acellular structures. The temperatures reached in CRF are known to cause collagen hyalinization [58], and histological studies have shown both axonal degeneration and collagen fiber destruction of the endo-, peri-, and epi-neurium structure occurs $[59,60]$. Clinical reports for the treatment of chronic pain have also shown that CRF produces lasting effects for years, but with reported long term side effects. Some of the side effects include deafferentation pain syndrome, neuritis, and paresthesia; all of which could indicate abnormal regeneration of the treated nerve [61]. Based on the extensive damage on the nerve structure and prolonged length of functional loss and side effects, these characteristics indicate that CRF produces a third or fourth degree injury with a potential for neuroma formation. Although CRF may produce long term efficacy, this method produces a higher chance of neuroma pain or reduced motor function in the long term.

PRF is a more recent development of the radiofrequency technology that is commonly used and is presented as a less destructive alternative to $\mathrm{CRF}$ by reducing the temperature to approximately 40 to $42^{\circ} \mathrm{C}$. Morphological analysis has shown transient endoneurial edema with a return to normal morphology by 7 days post-treatment, while clinical duration of effect has been found to last for months to years $[60,62]$. Since histological examination has determined that insignificant changes occur to the nerve and its surrounding structures, a distinctive mechanism of action is occurring [60]. At this point, the mechanism of action has not been identified. It appears that thermal energy does not create a neurodegenerative process to occur, it is believed that the electromagnetic field may be affecting the nerves, Schwann cells, and/or satellite cells $[60,63]$. Various studies have implied that PRF may either disrupt the neuronal membrane and function, gene expression change (c-Fos), and/or cytokine up-regulation [57,59]. At this point, the mechanism of action remains vague and more studies are required to elucidate the mechanism. Based on the known information, PRF does not fit into the five degrees of nerve injury and its mechanism of action vastly unique from the other treatment methods described in this article.

\section{Surgical Transection}

Nerve transection (neurectomy) is a permanent disruption of nerve function. Nerve transection is rarely used and considered a last resort treatment method for pain management or spasticity. As mentioned above, transection is a fifth degree nerve injury which results in a permanent loss of function with a likelihood of neuroma formation [64]. Clinical reports have indicated that this method has a reported pain recurrence rate ranging from $68 \%-78 \%[65,66]$. The recurrence of pain is likely due to neuroma formation, which leads to neuropathic pain.

Morphological studies have shown that the regenerating axon forms a non-neoplastic neuroma at the end of the transected nerve stump. The neuroma consist of disorganized myelinated axons wrapped in perineurial tissue [67]. Additionally, an increase in smaller disorganized myelinated fibers was observed post-treatment indicating the formation of nerve sprouts occurring within the neuroma [68]. Currently, various techniques for the prevention of neuroma formation are being studied with varying outcomes $[67,69]$.

\section{Discussion}

The methods described in this article detail several of the approaches that can be used in the treatment of neurological disorders relating to peripheral nerves. This article did not cover additional therapies, such as neurotoxins or high frequency nerve stimulation, as they fall outside the scope of nerve injury and regeneration. Table 2 provides an overview of each treatment method, as well as their associated degree of nerve injury and regeneration ability, based on the 
Page 5 of 7

analysis of available literature. With increasing degree of injury severity, the ability and rate of axon regeneration diminishes; thus, producing a longer duration of clinical effect. The consequences of increased degree of injury would also increase the deficit in the nerves ability to regenerate; while, the likelihood of neuroma formation and aberrations increases. The mildest treatments (i.e. lower concentrations of phenol/alcohol and cryoneuromodulation above $-60^{\circ} \mathrm{C}$ ) produce a second degree nerve injury, effective in reduction of pain or muscle spasticity with normal recovery of function over time.
More aggressive treatments (i.e. higher concentrations of phenol/ alcohol, CRF, and cryoneuromodulation below $-100^{\circ} \mathrm{C}$ ) that produce third to fourth degree nerve injuries can also produce an effective loss of nerve function, but with a deficit in the nerves ability to regenerate and increased probability of neuroma formations. While nerve transection produces the most severe type of nerve injury which results in a permanent effect with high likelihood of neuroma formation.

\begin{tabular}{|l|l|l|l|l|}
\hline Treatment Method & Primary Type of Targeted Nerve & $\begin{array}{l}\text { Duration of Clinical } \\
\text { Effect }\end{array}$ & $\begin{array}{l}\text { Degree of Nerve } \\
\text { Injury }\end{array}$ & Regeneration \\
\hline Phenol Injection & Sensory and Motor & Months to Years & 2nd to 3rd & Normal to Mild Deficit \\
\hline Alcohol Injection & Sensory and Motor & Months to Years & 2nd to 3rd & Normal to Mild Deficit \\
\hline Cryoneuromodulation $\left(<-100^{\circ} \mathrm{C}\right)$ & Sensory & Months to Years & 3rd & Mild Deficit \\
\hline Cryoneuromodulation $\left(-60^{\circ} \mathrm{C}\right)$ & Sensory; Emerging Use for Motor & Months to Years & 2nd & Normal \\
\hline Conventional Radiofrequency & Sensory & Months to Years & 3rd to 4th & Moderate to severe deficit \\
\hline Pulsed Radiofrequency & Sensory & Months to Years & N/A & N/A \\
\hline Transection & Sensory & Permanent & 5th & None \\
\hline
\end{tabular}

Table 2: Treatment Method and Degree of Resulting Nerve Injury

In deciding on the appropriate treatment method, the goals of the clinical results must be considered. Successful treatment of the symptoms will depend on a variety of factors including patient selection, effects on surrounding tissue, proper 'dosage', nerve type, proper nerve targeting, and/or application method. Depending on the mechanism of action initiated by each method, short and long term nerve regeneration results can vary markedly and should be considered in deciding a treatment for any nerve treatment. For example, post-thoracotomy pain is expected to last about a year. A treatment with a shorter duration of effect would be desired and a physician may choose a method that will cause a second degree nerve injury (such as cryoneuromodulation $\left(<-60^{\circ} \mathrm{C}\right)$ or lower concentrations of phenol/alcohol injection) which would last for months to a year, as opposed to CRF which tends to last for multiple years. Although it may seem desirable to use a more aggressive treatment for chronic long term pain symptoms, there is an increased risk of causing a neuroma; thus increasing the chance of overall pain symptoms. Therefore, repeat milder treatment may likely be a more desirable method as compared to a single aggressive treatment.

Another factor to consider is proximity of the targeted treatment site to other nearby tissues. In all the above mentioned methods, the treatments are non-selective and can disrupt any tissue type in the body. While cryoneuromodulation and radiofrequency treatments typically affect areas surrounding the probes of the device, injection of phenol and/or alcohol can spread to nearby structures. This is particularly important when unwanted injury to sensitive tissue that can cause unwanted side effects. At the same time, the localized nature of cryoneuromodulation and RF can create a challenging treatment when the precise location of a target nerve is not known. The small treatment zone surrounding the probes of these technologies requires that the tip be placed within a few millimeters from the target nerve. This can be mitigated through the use of imaging/guidance devices to help target the nerve location, such as transcutaneous electrical nerve stimulation, ultrasound, fluoroscopy, or other imaging technologies.
It is likely, in most treatment cases, that 2nd degree nerve injury would be the most desirable treatment outcome. Second degree injury appears to be best 'balanced' treatment when compared to 1st or 3rd degree nerve injury. Although 1st degree injury is associated with no risk of nerve regeneration, it is also has the shortest expected duration of effect. On the other end of the nerve injury spectrum, 3rd degree and higher nerve injury may produce longer term results, but with a risk of reduced re-innervation of the target organ and/or neuroma formation. Additionally, the risk is can be cumulative with repeat treatments over time. Due to the robust regenerative capacity of the axon in 2nd degree nerve injury, there is a more complete regeneration and re-innervation, along with a reasonable length of treatment efficacy.

\section{Conclusion}

This article details the various known mechanisms of action associated with a variety of treatments for peripheral nerve disorders and characterizes their degree of nerve injury as well as ability for nerve regeneration. Based on the known and expected results of the various mechanisms of action, a treatment that produces a 2 nd degree nerve injury will provide acceptable duration of treatment efficacy while allowing the nerve to regenerate and re-innervate its target organ. A 'higher dosage' of most of these methods (i.e high percentage phenol/alcohol or extremely low temperature cryoneuromodulation) can lead to 3rd or higher degree of injury; therefore, care must be taken to apply a safe and effective treatment. Additionally, a higher degree nerve injury can accumulate over time with repeated treatments; thus, leading to reduced motor or sensory function. Determining the appropriate method for a specific patient should be based on the clinical use and desired result as well as the potential for long-term healthy nerve regeneration. 


\section{References}

1. (2011) Relieving Pain in America: A Blueprint for Transforming Prevention, Care, Education, and Research. The National Academies Press.

2. Muthane UB, Ragothaman M, Gururaj G (2007) Epidemiology of Parkinson's disease and movement disorders in India: problems and possibilities. J Assoc Physicians India 55: 719-724.

3. Louis ED, Ferreira JJ (2010) How common is the most common adult movement disorder? Update on the worldwide prevalence of essential tremor. Mov Disord 25: 534-541.

4. Yiu G, He Z (2006) Glial inhibition of CNS axon regeneration. Nat Rev Neurosci 7: 617-627.

5. Madduri S, Gander B (2010) Schwann cell delivery of neurotrophic factors for peripheral nerve regeneration. J Peripher Nerv Syst 15: 93-103.

6. Wang JT, Medress ZA, Barres BA (2012) Axon degeneration: molecular mechanisms of a self-destruction pathway. J Cell Biol 196: 7-18.

7. Geuna S, Raimondo S, Ronchi G, Di Scipio F, Tos P, et al. (2009) Chapter 3: Histology of the peripheral nerve and changes occurring during nerve regeneration. Int Rev Neurobiol 87: 27-46

8. Belkas JS, Shoichet MS, Midha R (2004) Peripheral nerve regeneration through guidance tubes. Neurol Res 26: 151-160.

9. Hilliard MA (2009) Axonal degeneration and regeneration: a mechanistic tug-of-war. J Neurochem 108: 23-32.

10. Battiston B, Papalia I, Tos P, Geuna S (2009) Chapter 1: Peripheral nerve repair and regeneration research: a historical note. Int Rev Neurobiol 87: $1-7$.

11. Seddon HJ (1943) Three types of nerve injury. Brain. 66 .

12. Sunderland S (1951) A classification of peripheral nerve injuries producing loss of function. Brain 74: 491-516.

13. Evans PJ, Lloyd JW, Green CJ (1981) Cryoanalgesia: the response to alterations in freeze cycle and temperature. Br J Anaesth 53: 1121-1127.

14. Tetzlaff W, Bisby MA (1989) Neurofilament elongation into regenerating facial nerve axons. Neuroscience 29: 659-666.

15. Seil FJ (1983) Nerve, organ, and tissue regeneration--research perspectives. New York: Academic Press.

16. Taveggia C, Feltri ML, Wrabetz L (2010) Signals to promote myelin formation and repair. Nat Rev Neurol 6: 276-287.

17. Bosse F (2012) Extrinsic cellular and molecular mediators of peripheral axonal regeneration. Cell Tissue Res 349: 5-14.

18. Burnett MG, Zager EL (2004) Pathophysiology of peripheral nerve injury: a brief review. Neurosurg Focus 16: E1.

19. Sunderland S (1968) Nerves and Nerve Injuries. Edinburgh \& London: Livingstone.

20. Alant JD, Kemp SW, Khu KJ, Kumar R, Webb AA, et al. (2012) Traumatic neuroma in continuity injury model in rodents. Neurotrauma 29: 1691-1703.

21. Tos P, Artiaco S, Papalia I, Marcoccio I, Geuna S, et al. (2009) Chapter 14: End-to-side nerve regeneration: from the laboratory bench to clinical applications. Int Rev Neurobiol 87: 281-294.

22. Battiston B, Raimondo S, Tos P, Gaidano V, Audisio C, et al. (2009) Chapter 11: Tissue engineering of peripheral nerves. Int Rev Neurobiol 87: 227-249.

23. Siniscalco D, Giordano C, Rossi F, Maione S, de Novellis V (2011) Role of neurotrophins in neuropathic pain. Curr Neuropharmacol 9: 523-529.

24. Gruber H, Glodny B, Kopf H, Bendix N, Galiano K, et al. (2008) Practical experience with sonographically guided phenol instillation of stump neuroma: predictors of effects, success, and outcome. AJR Am J Roentgenol 190: 1263-1269.

25. Siemionow M, Brzezicki G (2009) Chapter 8: Current techniques and concepts in peripheral nerve repair. Int Rev Neurobiol 87: 141-172.

26. Daly W, Yao L, Zeugolis D, Windebank A, Pandit A (2012) A biomaterials approach to peripheral nerve regeneration: bridging the peripheral nerve gap and enhancing functional recovery. J R Soc Interface 9: 202-221.

27. Mottaghitalab F, Farokhi M, Zaminy A, Kokabi M, Soleimani M, et al. (2013) A biosynthetic nerve guide conduit based on silk/SWNT/ fibronectin nanocomposite for peripheral nerve regeneration. PLoS One 8: e74417.

28. May O (1912) The Functional And Histological Effects Of Intraneural And Intraganglionic Injections Of Alcohol. Br Med J 2: 465-470.

29. Kocabas H, Salli A, Demir AH, Ozerbil OM (2010) Comparison of phenol and alcohol neurolysis of tibial nerve motor branches to the gastrocnemius muscle for treatment of spastic foot after stroke: a randomized controlled pilot study. Eur J Phys Rehabil Med 46: 5-10.

30. Gruber H, Kovacs P, Peer S, Frischhut B, Bodner G (2004) Sonographically guided phenol injection in painful stump neuroma. AJR Am J Roentgenol 182: 952-954.

31. Watanabe A, Yamakage M (2011) Intrathecal neurolytic block in a patient with refractory cancer pain. J Anesth 25: 603-605.

32. Gracies JM, Elovic E, McGuire J, Simpson DM (1997) Traditional pharmacological treatments for spasticity. Part I: Local treatments. Muscle Nerve Suppl 6: S61-91.

33. Mooney V, Frykman G, McLamb J (1969) Current status of intraneural phenol injections. Clin Orthop Relat Res 63: 122-131.

34. Bodine-Fowler S1, Allsing S, Botte MJ (1996) Time course of muscle atrophy and recovery following a phenol-induced nerve block. Muscle Nerve 19: 497-504.

35. Westerlund T, Vuorinen V, Röyttä M (2001) Same axonal regeneration rate after different endoneurial response to intraneural glycerol and phenol injection. Acta Neuropathol 102: 41-54.

36. Baxter DW, Schacherl U (1962) Experimental studies on the morphological changes produced by intrathecal phenol. Can Med Assoc J 86: $1200-1205$

37. Labat G (1933) The Action of Alcohol on the Living Nerve: Experimental and Clinical Considerations. Anesthesia \& Analgesia 12: 190-196.

38. Trescot AM (2003) Cryoanalgesia in interventional pain management. Pain Physician 6: 345-360.

39. Moore W, Kolnick D, Tan J, Yu HS (2010) CT guided percutaneous cryoneurolysis for post thoracotomy pain syndrome: early experience and effectiveness. Acad Radiol 17: 603-606.

40. Zakrzewska JM, Nally FF (1988) The role of cryotherapy (cryoanalgesia) in the management of paroxysmal trigeminal neuralgia: a six year experience. Br J Oral Maxillofac Surg 26: 18-25.

41. Hodor L, Barkal K, Hatch-Fox LD (1997) Cryogenic denervation of the intermetatarsal space neuroma. J Foot Ankle Surg 36: 311-314.

42. Byas-Smith MG, Gulati A (2006) Ultrasound-guided intercostal nerve cryoablation. Anesth Analg 103: 1033-1035.

43. Nally FF (1984) A 22-year study of paroxysmal trigeminal neuralgia in 211 patients with a 3-year appraisal of the role of cryotherapy. Oral Surg Oral Med Oral Pathol 58: 17-23.

44. Waller A (1862) On the Sensory, Motory, and Vaso-Motory Symptoms Resulting from Refrigeration and Compression of the Ulnar and other Nerves in Man. Second Communication. Proceedings of the Royal Society of London 12: 89-103.

45. dos Santos MT, de Oliveira LM (2004) Use of cryotherapy to enhance mouth opening in patients with cerebral palsy. Spec Care Dentist 24: 232-234.

46. Allison SC, Abraham LD (2001) Sensitivity of qualitative and quantitative spasticity measures to clinical treatment with cryotherapy. Int J Rehabil Res 24: 15-24.

47. Algafly AA, George KP (2007) The effect of cryotherapy on nerve conduction velocity, pain threshold and pain tolerance. Br J Sports Med 41: 365-369.

48. Hsu M, Stevenson FF (2014) Reduction in muscular motility by selective focused cold therapy: a preclinical study. J Neural Transm 121: 15-20.

49. Navarro X, Vivó M, Valero-Cabré A (2007) Neural plasticity after peripheral nerve injury and regeneration. Prog Neurobiol 82: 163-201. 
Citation: Hsu M (2014) Significance of Clinical Treatments on Peripheral Nerve and its Effect on Nerve Regeneration . J Neurol Disord 2: 168. doi:10.4172/2329-6895.1000168

Page 7 of 7

50. Mazur P, Leibo SP, Chu EH (1972) A two-factor hypothesis of freezing injury. Evidence from Chinese hamster tissue-culture cells. Exp Cell Res 71:345-355

51. Gage AA, Baust J (1998) Mechanisms of tissue injury in cryosurgery. Cryobiology 37: 171-186.

52. Erinjeri JP, Clark TW (2010) Cryoablation: mechanism of action and devices. J Vasc Interv Radiol 21: S187-191.

53. Zhou L, Kambin P, Casey KF, Bonner FJ, O'Brien E, et al. (1995) Mechanism research of cryoanalgesia. Neurol Res 17: 307-311.

54. Kerns JM, Braverman B, Mathew A, Lucchinetti C, Ivankovich AD (1991) A comparison of cryoprobe and crush lesions in the rat sciatic nerve. Pain 47: 31-39.

55. Zhou L, Shao Z, Ou S (2003) Cryoanalgesia: electrophysiology at different temperatures. Cryobiology 46: 26-32.

56. Tun K, Cemil B, Gurcay AG, Kaptanoglu E, Sargon MF, et al. (2009) Ultrastructural evaluation of Pulsed Radiofrequency and Conventional Radiofrequency lesions in rat sciatic nerve. Surg Neurol 72: 496-500.

57. Van Zundert J, de Louw AJ, Joosten EA, Kessels AG, Honig W, et al. (2005) Pulsed and continuous radiofrequency current adjacent to the cervical dorsal root ganglion of the rat induces late cellular activity in the dorsal horn. Anesthesiology 102: 125-131.

58. Hayashi K, Thabit G 3rd, Massa KL, Bogdanske JJ, Cooley AJ, et al (1997) The effect of thermal heating on the length and histologic properties of the glenohumeral joint capsule. Am J Sports Med 25: 107-112.

59. Choi S, Choi HJ, Cheong Y, Lim YJ, Park HK (2013) Internal-specific morphological analysis of sciatic nerve fibers in a radiofrequencyinduced animal neuropathic pain model. PLoS One 8: e73913.

60. Podhajsky RJ, Sekiguchi Y, Kikuchi S, Myers RR (2005) The histologic effects of pulsed and continuous radiofrequency lesions at 42 degrees $\mathrm{C}$ to rat dorsal root ganglion and sciatic nerve. Spine (Phila Pa 1976) 30: 1008-1013.

61. Vu T, Chhatre A (2014) Cooled radiofrequency ablation for bilateral greater occipital neuralgia. Case Rep Neurol Med 2014: 257373.

62. Vallejo R, Tilley DM, Williams J, Labak S, Aliaga L, et al. (2013) Pulsed radiofrequency modulates pain regulatory gene expression along the nociceptive pathway. Pain Physician 16: E601-613.

63. Erdine S, Bilir A, Cosman ER, Cosman ER Jr (2009) Ultrastructural changes in axons following exposure to pulsed radiofrequency fields. Pain Pract 9: 407-417.

64. Zochodne DW, Nguyen C (1997) Angiogenesis at the site of neuroma formation in transected peripheral nerve. J Anat $191: 23-30$.

65. Zacest AC, Magill ST, Anderson VC, Burchiel KJ (2010) Long-term outcome following ilioinguinal neurectomy for chronic pain. J Neurosurg 112: 784-789.

66. Oturai AB, Jensen K, Eriksen J, Madsen F (1996) Neurosurgery for trigeminal neuralgia: comparison of alcohol block, neurectomy, and radiofrequency coagulation. Clin J Pain 12: 311-315.

67. Ko JH, Kim PS, O'Shaughnessy KD, Ding X, Kuiken TA, et al (2011) A quantitative evaluation of gross versus histologic neuroma formation in a rabbit forelimb amputation model: potential implications for the operative treatment and study of neuromas. J Brachial Plex Peripher Nerve Inj 6: 8 .

68. Kim PS, Ko J, O'Shaughnessy KK, Kuiken TA, Dumanian GA (2010) Novel model for end-neuroma formation in the amputated rabbit forelimb. J Brachial Plex Peripher Nerve Inj 5: 6.

69. Yan H, Zhang F, Kolkin J, Wang C, Xia Z, et al. (2014) Mechanisms of nerve capping technique in prevention of painful neuroma formation. PLoS One 9: e93973. 